\title{
Management of postoperative complications may favour the centralization of distal pancreatectomies. Nationwide data on pancreatic distal resections in Finland 2012-2014
}

\author{
Antila, A.
}

2019-01

Antila , A , Ahola , R , Sand , J \& Laukkarinen , J 2019 , ' Management of postoperative complications may favour the centralization of distal pancreatectomies. Nationwide data on pancreatic distal resections in Finland 2012-2014 ' , Pancreatology, vol. 19 , no. 1 , pp. 26-30 . https://doi.org/10.1016/j.pan.2018.11.012

http://hdl.handle.net/10138/312542

https://doi.org/10.1016/j.pan.2018.11.012

publishedVersion

Downloaded from Helda, University of Helsinki institutional repository.

This is an electronic reprint of the original article.

This reprint may differ from the original in pagination and typographic detail.

Please cite the original version. 


\title{
Management of postoperative complications may favour the centralization of distal pancreatectomies. Nationwide data on pancreatic distal resections in Finland 2012-2014
}

\author{
A. Antila a, R. Ahola a , J. Sand ${ }^{\text {b }}$, J. Laukkarinen ${ }^{\text {a, c, }}$ " \\ ${ }^{a}$ Department of Gastroenterology and Alimentary Tract Surgery, Tampere University Hospital, Tampere, Finland \\ b Päijät-Häme Central Hospital, Lahti, Finland \\ ${ }^{\mathrm{c}}$ Faculty of Medicine and Life Sciences, University of Tampere, Tampere, Finland
}

\section{A R T I C L E I N F O}

\section{Article history:}

Received 30 July 2018

Received in revised form

22 November 2018

Accepted 23 November 2018

Available online 30 November 2018

\section{Keywords:}

Pancreatic distal resection

Pancreatic fistula

Hospital volume

Centralization

Complication

\begin{abstract}
A B S T R A C T
Background: Centralization of pancreatic surgery has proceeded in the last few years in many countries. However, information on the effect of hospital volume specifically on distal pancreatic resections (DP) is lacking.

Aim: To investigate the effect of hospital volume on postoperative complications in DP patients in Finland.

Methods: All DP performed in Finland during the period 2012-2014 were analyzed, information having been retrieved from the appropriate national registers. Hospital volumes, postoperative pancreatic fistulae (POPF) and overall complications were graded. High volume centre (HVC) was defined as performing > 10 DPs, median volume centre (MVC) 4-9 DPs and low volume centre (LVC) fewer than 4 DP annually.

Results: A total of 194 DPs were performed at 18 different hospitals. Of these $42 \%$ (81) were performed in HVCs (2 hospitals), 43\% (84) in MVCs (6 hospitals) and the remaining 15\% (29) in LVCs (10 hospitals). Patient demographics did not differ between the hospital volume groups. The overall rate of clinically relevant POPF, Clavien-Dindo grade 3-5 complications, and 90-day mortality showed no significant differences between the different hospital volumes. Grade C POPF was found more often in LVCs, being $1.2 \%$ in HVCs, $0 \%$ in MCVs and $6.9 \%$ in LVCs, $\mathrm{p}=0.030$. More reoperations were performed in LVCs (10.3\%) than in HVCs $(1.2 \%)$ or MVCs (1.2\%); $\mathrm{p}=0.025$.

Conclusions: Even though the rate of postoperative complications after DP is not affected by hospital volume, reoperations were performed ten times more often in the low-volume centres. Optimal management of postoperative complications may favour centralization not only of PD, but also of DP. () 2018 IAP and EPC. Published by Elsevier B.V. All rights reserved.
\end{abstract}

\section{Introduction}

Centralization of treatment of pancreatic surgery reduces postoperative mortality and morbidity and also improves longterm survival after pancreatoduodenectomy (PD) [1-4]. Compared to PD, postoperative pancreatic fistulas (POPF) are even more common - though less life-threatening - after distal pancreatectomy (DP) and overall morbidity also remains high [5-7]. The effect of hospital volume on complications after DP has

\footnotetext{
* Corresponding author. Dept. of Gastroenterology and Alimentary Tract Surgery, Tampere University Hospital, Teiskontie 35, 33521, Tampere, Finland.
}

E-mail address: johanna.laukkarinen@fimnet.fi (J. Laukkarinen). not been widely studied [8]. The aim of this study was to analyze whether hospital volume affects the rate of POPF and overall morbidity after DP according to a nationwide database.

\section{Methods}

All patients undergoing DP in the period 2012-2014 were identified from the Finnish Operation and Treatment Register (HILMO) using Nordic Classification of Surgical Procedures codes (ICD10 codes JLC10 and JLC11). All patient records were collected and examined manually. Emergency operations and patients with no data available were excluded.

Postoperative complications, POPF, mortality, reoperations and 
hospital stay were registered. Data on the course of the surgery was also gathered. Complications were graded according to the ClavienDindo classification and grades 3-5 were considered major complications [9]. Postoperative pancreatic fistulas were graded according to the new ISGPF classification $[10,11]$. In grade B fistula the drain is left in place for over 3 weeks or repositioned through percutaneous or endoscopic procedures. Grade $C$ fistula requires either reoperation or leads to organ failure or death of the patient. The final histopathological diagnoses were also gathered.

The hospital DP volumes were calculated and the hospitals were categorized according to operation volume. For this study, highvolume centres (HVC) were defined as those performing 10 or more distal pancreatectomies per year Median-volume centres (MVC) accomplished 4-9 DPs and low-volume centres (LVC) less than 4 DPs per year.

Ethical approval for the study was granted by the Regional Ethics Committee of Pirkanmaa, Finland (ETL code R12241).

\section{Statistical analysis}

Fisher's exact test and $\times 2$ test were used as appropriate to calculate statistical differences. Statistical analysis was performed with IBS SPSS statistics software. $\mathrm{P} \leq 0.05$ was considered statistically significant.

\section{Results}

One hundred and ninety-four DPs were performed in Finland between 2012 and 2014 in 18 different hospitals. There were two HVCs, 6 MVCs, and 10 LVCs. Of DPs 85\% (165) were performed in HVCs and MVCs (41\% in HCVs and 44\% in MVCs) and 15\% (29) in LVCs. In total $81 \mathrm{DP} / 3 \mathrm{yr}$ were performed in HVCs, 84 in MVCs and 29 in LVCs.

Patient demographics or perioperative data did not differ between the centres (Table 1). Combined splenectomy (median $60 \%$, range $51-69 \%$ ) and resection of other organs (16\%, range $11-20 \%$ ) were performed without differences between the centres. Blood loss (median $700 \mathrm{ml}$, range $10-16000 \mathrm{ml}$ ) and operative time (median $187 \mathrm{~min}$, range $114-317 \mathrm{~min}$ ) were also similar regardless of hospital volume. For pancreatic stump closure stapler was used in $69 \%$ of patients, and the methods did not differ between the groups. There were more laparoscopic procedures in HVCs and MVCs than in LVCs $(28 \%, 27 \%$ and $3 \%$ respectively, $\mathrm{p}=0.008)$.

The proportion of malignant diseases was similar between the centres. The final histopathological diagnoses are shown in Table 2.

The overall rate for POPF $(\mathrm{B} / \mathrm{C})$ rate was $17.2 \%$ in all patients. POPF occurred in $21 \%$ in HVCs, $10.7 \%$ in MVCs and $17.2 \%$ in LVCs.
Table 2

Final histopathological diagnoses: all patients.

\begin{tabular}{ll}
\hline Adenocarcinoma & $40(21 \%)$ \\
Neuroendocrine carcinoma & $7(3,6 \%)$ \\
Intraductal papillary mucinous carcinoma & $2(1 \%)$ \\
Gastrointestinal stromal carcinoma & $1(0,5 \%)$ \\
Kidney metastasis & $6(3 \%)$ \\
Colon carcinoma & $1(0,5 \%)$ \\
Neuroendocrine tumour & $43(22, \%)$ \\
Mucinous cystic nesplasm & $23(11,9 \%)$ \\
Intraductal papillary mucinous neoplasm & $17(8,8 \%)$ \\
Serous cystic neoplasm & $20(10 \%)$ \\
Solid pseudopapillary neoplasm & $3(1,5 \%)$ \\
Chronic pancreatitis & $7(3,6 \%)$ \\
Pseudocyst & $7(3,6 \%)$ \\
Gastrointestinal stromal tumour & $1(0,5 \%)$ \\
Cyst & $5(2,6 \%)$ \\
Fibrosis & $1(0,5 \%)$ \\
Spleen accessorius & $7(3,6 \%)$ \\
Hemangioma & $1(0,5 \%)$ \\
Nesidioblastooma & $1(0,5 \%)$ \\
\hline
\end{tabular}

Grade C POPF was found more often in LVCs, the rate being $1.2 \%$ in HVCs, $0 \%$ in MCVs and $6.9 \%$ in LVCs, $\mathrm{p}=0.030$. The rate of intraabdominal collections was similar; they occurred respectively in $28 \%, 25 \%$, and $20.7 \%$ in HVCs, MVCs and LVCs. Interventional drain or pancreatic stent was used similarly in the centres to drain a collection in the postoperative treatment of POPF. Delayed gastric emptying (DGE) was found to be more common in LVCs $(20.7 \%)$ than in HVCs/MVCs (3.7\%/10.7\%; $\mathrm{p}=0.018)$. However, no difference was found in other complications such as postoperative pancreatitis, lymphatic leak, post-pancreatic hemorrhage ( $\mathrm{PPH})$, wound infection, pneumonia or pulmonary embolism (Table 3 ).

Clavien-Dindo 3-5 complications occurred in $16.0 \%$ of HVC patients, in MVCs in $18.1 \%$ of patients, and in LVCs in $20.7 \%$ of patients. In LVCs the rate for major complications tended to be higher, but this was not statistically significant $(\mathrm{p}=0.81)$. Ninety-day mortality was $0 \%$ in HVCs and in the LVC group and $2.4 \%$ in MVCs.

Significantly more reoperations were performed in LVCs, on $10.3 \%$ of patients $(3 / 29)$, than in HVCs and MVCs: $1.2 \%(1 / 82)$ and $1.2 \%(1 / 87)$ respectively, $p=0.025$. Due to the small number of reoperations, multivariate analysis was not possible. Out of the three re-operated patients in the LVCs, the first patient had POPF, $\mathrm{PPH}$ and pneumonia and was treated in the ICU. He underwent reoperation twice; on day 19 due to $\mathrm{PPH}$ and intra-abdominal collection (splenectomy and drain repositioned) and on day 49 due to $15 \mathrm{~cm}$ wide peripancreatic collection with amylase-rich fluid (drain repositioned). The second patient underwent reoperation on

Table 1

Pre- and perioperative characteristics across the groups.

\begin{tabular}{|c|c|c|c|c|c|}
\hline & $\begin{array}{l}\text { High-Volume centre } \mathrm{n} \\
(\mathrm{DP})=81\end{array}$ & $\begin{array}{l}\text { Medium-volume centre } \\
n(D P)=84\end{array}$ & $\begin{array}{l}\text { Low-volume centre } \mathrm{n} \\
(\mathrm{DP})=29\end{array}$ & $\begin{array}{l}\text { Overall volume } n \\
(D P)=194\end{array}$ & \\
\hline Age, median, years (range) & $62(0.3-80)$ & $65(21-80)$ & $67(41-85)$ & $64(0,3-85)$ & \\
\hline Sex ratio $(F / M)$ & $45 / 36$ & $60 / 24$ & $17 / 12$ & $122 / 72$ & \\
\hline BMI & $26,1(16-40)$ & $23,6(19-40)$ & $28,4(23-36)$ & $26,1(16-40)$ & \\
\hline Diabetes & $20(24,7 \%)$ & $10(14,1 \%)$ & $8(29,6 \%)$ & $21,2 \%(38)$ & \\
\hline Laparoscopic procedure & $23(28,4 \%)$ & $23(27,4 \%)$ & $1(3,4 \%)$ & $47(24,2 \%)$ & $\mathrm{p}=0.008$ \\
\hline $\begin{array}{l}\text { Combined resection of other } \\
\text { organs }\end{array}$ & $9(11,1 \%)$ & $17(20,2 \%)$ & $4(13,8 \%)$ & $30(15,5 \%)$ & \\
\hline $\begin{array}{l}\text { Hand -sewn closure of the } \\
\text { pancreatic }\end{array}$ & $25(30,9 \%)$ & $20(23,8 \%)$ & $11(37,9 \%)$ & $56(28,9 \%)$ & \\
\hline Stapler closure of pancreatic stump & $54(66,7 \%)$ & $64(76,2 \%)$ & $16(55,2 \%)$ & $134(69,1 \%)$ & \\
\hline Splenectomy & $42(51,9 \%)$ & $58(69,0 \%)$ & $16(55,2 \%)$ & $116(59,8 \%)$ & \\
\hline Blood loss (ml) & $850(150-5300)$ & $590(0-16000)$ & $500(300-2500)$ & $700(0-16000)$ & \\
\hline Oper. time (min) & $167(115-317)$ & $200(114-377)$ & $180(120-258)$ & $187(114-377)$ & \\
\hline Number of hospitals & 2 & 6 & 10 & 18 & \\
\hline
\end{tabular}


Table 3

Postoperative complications in the groups.

\begin{tabular}{|c|c|c|c|c|}
\hline$\%(\mathrm{n})$ & High-volume centre $\mathrm{n}=81$ & Medium-volume centre $\mathrm{n}=84$ & Low-volume centre $n=29$ & \\
\hline \multicolumn{5}{|l|}{ Pancreatic Fistula } \\
\hline Grade B & $19,8 \%(16)$ & $10,7 \%(9)$ & $10,3 \%(3)$ & \\
\hline Grade C & $1,2 \%(1)$ & $0,0 \%(0)$ & $6,9 \%(2)$ & $P=0,030$ \\
\hline Grade $\mathrm{B} / \mathrm{C}$ & $21,0 \%(17)$ & $10.7 \%(9)$ & $17,2 \%(5)$ & \\
\hline $\mathrm{PPH}$ & $4,9 \%(4)$ & $4,8 \%(4)$ & $6,9 \%(2)$ & \\
\hline DGE & $3,7 \%(3)$ & $10,7 \%(9)$ & $20,7 \%(6)$ & $P=0,018$ \\
\hline Intra-abdominal collection & $28,4 \%(23)$ & $25,0 \%(21)$ & $20,7 \%(6)$ & \\
\hline Interventional drain & $13,6 \%(11)$ & $11,9 \%(10)$ & $10,3 \%(3)$ & \\
\hline Pancreatic stent & $2,5 \%(2)$ & $2,4 \%(2)$ & $6,9 \%(2)$ & \\
\hline CT verified pancreatitis & $3,7 \%(3)$ & $2,4 \%(2)$ & $0,0 \%(0)$ & \\
\hline Lympha leak & $1,2 \%(1)$ & $1,2 \%(1)$ & $0,0 \%(0)$ & \\
\hline Wound-infection & $9,9 \%(8)$ & $3,6 \%(3)$ & $10,3 \%(3)$ & \\
\hline Pneumonia & $12,3 \%(10)$ & $6,0 \%(5)$ & $10,3 \%(3)$ & \\
\hline Pulmonary embolism & $3,7 \%(3)$ & $0,0 \%(0)$ & $5,0 \%(1)$ & \\
\hline Clavien-Dindo III-V & $16,0 \%(13)$ & $18,1 \%(15)$ & $20,7 \%(6)$ & \\
\hline Reoperation & $1,2 \%(1)$ & $1,2 \%(1)$ & $10,3 \%(3)$ & $\mathrm{p}=0,025$ \\
\hline Total hospital stay, median (range) & $7(3-25)$ & $8(3-30)$ & $8(5-40)$ & \\
\hline Readmission & $16,3 \%(13)$ & $13,1 \%(11)$ & $24,1 \%(7)$ & \\
\hline 90-day mortality & $0,0 \%(0)$ & $2,4 \%(2)$ & $0,0 \%(0)$ & \\
\hline
\end{tabular}

day 8 due to infection and inadequate blood flow to the spleen seen in ultrasound (splenectomy, drain repositioned; produced amylaserich fluid). The third patient underwent reoperation on day 10 due to DGE (nasogastric tube repositioned, inflammation detected around pancreas with jejunal loops attached). The indications for reoperations in the HVC group were bowel necrosis caused by atherosclerosis and prolonged infection due to POPF, and in the MVC group ureter injury sustained in the primary operation. Clavien-Dindo complication, reoperation and readdmission rates are seen in Fig. 1.

There were no differences in total hospital stay, readmission rate or 90-day mortality. These parameters are shown in Table 3. There were two deaths within 90 days postoperatively, both in the MVC group. The first patient died on day 3. This patient had a BMI of 40 , and had breathing problems before his death, probably because of a pulmonary embolism. The second patient died on day 12 due to postoperative bleeding. Hemoglobin level was $23 \mathrm{~g} / \mathrm{l}$ before her death. She also had cholangitis and a choledochal stone had been removed in endoscopic retrograde cholangiography (ERC) 2 days earlier.

In univariate analysis, no single factor significantly affecting the formation of clinically relevant POPF was found. In all open procedures the clinically relevant fistula rate was $17.2 \%$ and in the laparoscopic procedures $12.8 \%$ (ns). Combined resection of other

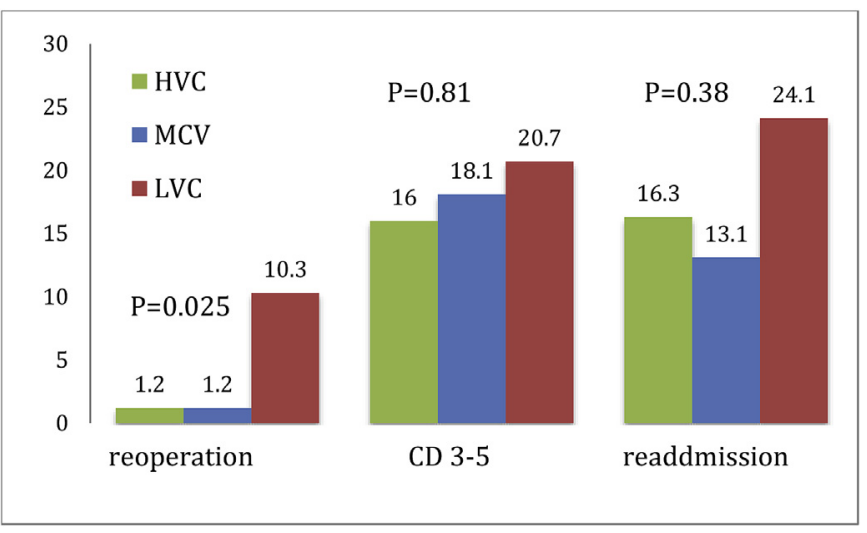

Fig. 1. Reoperation, Clavien-Dindo 3-5 grades and readdmission rates seen in different centres. $\mathrm{HVC}=$ high volume centre, $\mathrm{MVC}=$ median volume centre, $\mathrm{LVC}=$ low volume centre). organs raised the fistula rate up to $23.3 \%$ but without a significant difference between different centre volumes. In stapler closure and in hand sewn closure groups the respective fistula rates were $17 \%$ and $17.0 \%$ (ns). Malignancy did not protect against fistula formation, the POPF rate being $14,2 \%$ in all malignant cases.

\section{Discussion}

Ample evidence supports the centralization of PDs [12-16], but it is not known whether it would be beneficial also to centralize DPs. Our aim was to study the effect of hospital volume on the outcome of all DP operations performed nationwide in Finland during the period 2012-2014. We found that the frequencies of clinically relevant POPF and Clavien-Dindo $3-5$ complications were not related to hospital volume. However, the management of complications differed significantly, as more reoperations were performed in the LVCs.

The reoperation rate in LVC was $10.3 \%$ and included three patients. One might speculate that these were all unnecessary. The first patient with PPH, POPF and intra-abdominal collection, who twice underwent relaparotomy, could have been managed by interventional radiological procedures. The second patient who had an infection and inadequate blood flow to the spleen on ultrasound could have been managed without laparotomy if a CT scan had been performed. The third patient who underwent a laparotomy for DGE could have been managed by watchful waiting, medical treatment, and repeated imaging. Most of the postoperative complications, which in the past may have needed surgery, can today be treated with conservative or minimally invasive approaches. In the lowvolume centres the options for modern treatment may be limited.

A laparoscopic approach was taken, most often in HVCs and MVCs. Overall, laparoscopy seems to be underutilized in DPs in Finland, as the overall rate is so low (24\%). Laparoscopic DP is associated with significantly less overall morbidity than open technique. Blood loss is smaller and the length of hospital stay is shorter [17]. However, no significant difference in clinically relevant POPF was found. In the LVCs laparoscopic approach was rare which might be explained by the low volume affecting the learning process. Thus, centralizing the procedures to at least MVC/HVC level might be beneficial even in this respect.

The overall clinically relevant POPF rate in our study was $17.2 \%$, which is comparable to what has been reported elsewhere. Postoperative complications occur even in HVCs, and also in this study 
no significant difference was found either in the incidence of POPF or in Clavien-Dindo 3-5 complications. Nor has a decrease in overall complication rate or POPF rate after DP been reported in HVCs vs. LVCs in the literature. However, only few studies report the rates of complications after DP separately [8]. In our study, DGE seemed to be more common in LVCs, but the patient records may not have all the information reliably listed.

Several studies have reported an association between high hospital volume and lower postoperative mortality in pancreatic surgery [1,2]. It has been shown that higher mortality in low volume centres with high-risk surgery is associated with the hospital's ability to rescue patients from major complications $[3,18]$ The mortality risk is also attributable to patient characteristics, such as age and comorbidity [19]. In this study the deaths occurred in the MVC group and were both sudden and not caused by a treated complication, but one of them was associated with comorbidity, i.e., obesity.

PD has been shown to carry lower mortality and morbidity and also better oncological outcome in high-volume centres $[1,20]$. So far, centralization of DPs in high-volume centres does not seem to occur, although only few studies have been presented concerning only DPs in terms of postoperative complications and hospital volume [8]. One article which claimed that pancreatic resections can be safely done in MVCs had only $13 \mathrm{DP} / 11$ yrs with a clinically relevant POPF rate in DP of 32\% [21]. Factors favoring centralizing DP as well as PD include the overall knowledge of pancreatic surgery and its complications and postoperative care. Treatment and care may require imaging and interventional radiology around-theclock and the decision-making for treatment also needs a multidisciplinary approach, which is often lacking in LVC units. Reasonable volumes are needed to achieve and maintain experienced perioperative management. When analysing all patient records from each hospital manually we found no differences between HVCs and LVCs in terms of equipment used in surgery. Time of drain removal varies within centres according to individual surgeon. However, we did find that multidisciplinary teams were used in all tertiary but only in some secondary hospitals (HVCs and MCVs) and in neither of the LVC hospitals. In Finland, where the population is only 5.4 million and both DP and PC volumes are generally small, it would be wise to centralize the know-how in fewer centres in order to achieve the best results.

Risk factors for POPF have been widely studied. A laparoscopic approach has been shown to reduce the overall complications, but not POPF [22]. Many closure methods for pancreatic stump have been developed to reduce the complications, especially POPF. The pancreas can be closed by suturing or staplers, the stump can be covered with various patches or meshes or Tachosil [23]. Pancreatico-jejunal anastomosis and preoperative pancreatic stent have also been used [24,25]. Neither of these has reduced the POPF rate in RCTs. In a recent RCT a ligament Teres patch was shown to significantly decrease reoperation, readmission and reintervention rates without affecting the POPF rate [26]. On the pharmaceutical side, the use of octreotide is controversial. It has no effect on clinically relevant POPF, but it may reduce overall morbidity [27]. Pasireotide has been shown to reduce POPF rate to 7\% after DP, in a recent RCT. High BMI has also been shown to increase the morbidity rate $[28,29]$. The effect of hospital volume in DP only has been poorly reported.

The strength of this study is the nationwide coverage of all DP operations performed in a single country during the study period. The study provides valuable information on nationwide DP volumes and complications rates. This is the first nationwide study on DP in Europe.

The weaknesses of this study include the missing and incomplete data. Patient data was collected retrospectively from 18 different hospitals in Finland and analyzed manually. POPF classification was made according the data found by the authors, so the analysis is consistent throughout the study [11]. Octreotide was not used routinely in any of the hospitals studied, although some surgeons did use it occasionally. It is therefore no included in the analysis. We could find no accurate information on drain removal time and were therefore unable to include this in the data. . Overall, the information is missing randomly and should not affect the results. The hospital volume definition is somewhat arbitrary, as in the literature definitions of volume mostly include both DP and PD. The number of patients in this study is also rather low since DP was performed quite rarely, which is also weakness of the study.

In conclusion, this nationwide register study shows similar POPF and overall complication rates after DPs performed in different volume hospitals in Finland during the period 2012-1014. However, there was a significant difference in the management of postoperative complications, as the reoperation rate was significantly more common in the LVCs. With experienced postoperative management, reoperations could possibly be avoided. This may favour the centralization of pancreatic resections to HVCs - not only for PD, but also for DP.

\section{Acknowledgements}

This work was supported by the State Research Funding (VTR), Finland, and the Sigrid Juselius Foundation, Finland. The authors declare that they have no conflicts of interest. The authors thank statistician M. Helminen (University of Tampere) for help with data analyzing.

\section{References}

[1] Ahola R, Siiki A, Vasama K, et al. Effect of centralization on long-term survival after resection of pancreatic ductal adenocarcinoma. Br J Surg 2017;104: 1532-8.

[2] Gooiker GA, van Gijn W, Wouters MW, et al. Systematic review and metaanalysis of the volume-outcome relationship in pancreatic surgery. Br J Surg 2011:98:485-94.

[3] Ghaferi AA, Birkmeyer JD, Dimick JB. Hospital volume and failure to rescue with high-risk surgery. Med Care 2011;49:1076-81.

[4] Bliss LA, Yang CJ, Chau Z, et al. Patient selection and the volume effect in pancreatic surgery: unequal benefits? HPB 2014;16:899-906.

[5] Sledzianowski JF, Duffas JP, Muscari F, et al. Risk factors for mortality and intra-abdominal morbidity after distal pancreatectomy. Surgery 2005;137: $180-5$

[6] McMillan MT, Christein JD, Callery MP, et al. Comparing the burden of pancreatic fistulas after pancreatoduodenectomy and distal pancreatectomy. Surgery 2016;159:1013-22.

[7] McMillan MT, Christein JD, Callery MP, et al. Comparing the burden of pancreatic fistulas after pancreatoduodenectomy and distal pancreatectomy. Surgery 2016:159:1013-22.

[8] Rosales-Velderrain A, Bowers SP, Goldberg RF, et al. National trends in resection of the distal pancreas. World J Gastroenterol 2012;18:4342-9.

[9] Dindo D, Demartines N, Clavien PA. Classification of surgical complications: a new proposal with evaluation in a cohort of 6336 patients and results of a survey. Ann Surg 2004;240:205-13.

[10] Bassi C, Dervenis C, Butturini G, et al. Postoperative pancreatic fistula: an international study group (ISGPF) definition. Surgery 2005;138:8-13.

[11] Bassi C, Marchegiani G, Dervenis C, et al. The 2016 update of the International Study Group (ISGPS) definition and grading of postoperative pancreatic fistula: 11 Years after. Surgery 2017;161:584-91.

[12] Derogar M, Blomberg J, Sadr-Azodi O. Hospital teaching status and volume related to mortality after pancreatic cancer surgery in a national cohort. $\mathrm{Br} \mathrm{J}$ Surg 2015;102:57. discussion 557.

[13] Birkmeyer JD, Stukel TA, Siewers AE, et al. Surgeon volume and operative mortality in the United States. N Engl J Med 2003;349:2117-27.

[14] Goodney PP, Siewers AE, Stukel TA, et al. Is surgery getting safer? National trends in operative mortality. J Am Coll Surg 2002;195:219-27.

[15] Gooiker GA, van Gijn W, Wouters MW, et al. Systematic review and metaanalysis of the volume-outcome relationship in pancreatic surgery. Br J Surg 2011;98:485-94.

[16] Soreide JA, Sandvik OM, Soreide K. Improving pancreas surgery over time: performance factors related to transition of care and patient volume. Int J Surg 2016;32:116-22.

[17] Venkat R, Edil BH, Schulick RD, et al. Laparoscopic distal pancreatectomy is 
associated with significantly less overall morbidity compared to the open technique: a systematic review and meta-analysis. Ann Surg 2012;255: $1048-59$.

[18] Reames BN, Ghaferi AA, Birkmeyer JD, et al. Hospital volume and operative mortality in the modern era. Ann Surg 2014;260:244-51.

[19] LaPar DJ, Kron IL, Jones DR, et al. Hospital procedure volume should not be used as a measure of surgical quality. Ann Surg 2012;256:606-15.

[20] Ansari D, Williamsson C, Tingstedt B, et al. Pancreaticoduodenectomy-the transition from a low- to a high-volume center. Scand J Gastroenterol 2014;49:481-4.

[21] Peros G, Giannopoulos GA, Christodoulou S, et al. Good results after major pancreatic resections in a middle-volume center. Pancreas 2010;39:411-4.

[22] Venkat R, Edil BH, Schulick RD, et al. Laparoscopic distal pancreatectomy is associated with significantly less overall morbidity compared to the open technique: a systematic review and meta-analysis. Ann Surg 2012;255: 1048-59.

[23] Park JS, Lee DH, Jang JY, et al. Use of TachoSil((R)) patches to prevent pancreatic leaks after distal pancreatectomy: a prospective, multicenter, randomized controlled study. J Hepatobiliary Pancreat Sci 2016;23:110-7.

[24] Antila A, Sand J, Nordback I, et al. Is Roux-Y binding pancreaticojejuna anastomosis feasible for patients undergoing left pancreatectomy? Results from a prospective randomized trial. BioMed Res Int 2014;2014:508714.

[25] Frozanpor F, Lundell L, Segersvard R, et al. The effect of prophylactic transpapillary pancreatic stent insertion on clinically significant leak rate following distal pancreatectomy: results of a prospective controlled clinical trial. Ann Surg 2012;255:1032-6.

[26] Hassenpflug M, Hinz U, Strobel O, et al. Teres ligament patch reduces relevant morbidity after distal pancreatectomy (the DISCOVER randomized controlled trial). Ann Surg 2016;264:723-30.

[27] Allen PJ, Gonen M, Brennan MF, et al. Pasireotide for postoperative pancreatic fistula. N Engl J Med 2014;370:2014-22.

[28] Seeliger H, Christians S, Angele MK, et al. Risk factors for surgical complications in distal pancreatectomy. Am J Surg 2010;200:311-7.

[29] Sledzianowski JF, Duffas JP, Muscari F, et al. Risk factors for mortality an intra-abdominal morbidity after distal pancreatectomy. Surgery 2005;137: 180-5. 